\title{
Bioacoustic: Percentage Click Sound of Indo-Pacific Bottlenose Dolphins (Tursiops Aduncus) in Captivity, Indonesia
}

Lubis $\mathrm{MZ}^{1 *}$, Wulandari PD${ }^{1}$, Harahap $\mathrm{MS}^{2}$, Tauhid $\mathrm{M}^{3}$, Moron $\mathrm{JR}^{4}$ and Stansbury $\mathrm{A}^{5}$

${ }^{1}$ Department of Marine Science and Technology, Bogor Agricultural University, Indonesia

${ }^{2}$ Department of Marine Fisheries and Livestock Production, North Labuhanbatu Goverment, Indonesia

${ }^{3}$ Department of Marine Fisheries, Bima Goverment, Indonesia

${ }^{4}$ Departament of Biology (BIO), Federal University of Juiz de Fora, Sao Paulo Brazil

${ }^{5}$ Scottish Oceans Institute, University of St. Andrews, UK

\begin{abstract}
Bioacoustics is a combination between biology and acoustic study which usually refers to a study on sound production, dispersion through elastic media, and reception in animals, including humans. Bio sonar signals dolphin radiated along the beam axis of an Atlantic bottlenose dolphin resemble short transient oscillations. The purpose of this research is to measure, analyse, distinguish dolphin sound characteristics and detect the click sound by the dolphins. Indo-pacific bottlenose dolphins, maintained in captivity, Indonesia, had the lowest intensity of $18.76 \mathrm{~dB}$ while the highest were $32.02 \mathrm{~dB}$ with $100 \%$ percentage. Sound frequency range of Indo-pacific bottlenose dolphins in captivity, Indonesia was between $13.211-15.245 \mathrm{~Hz}$. The percentage maximum intensity in the frequency is 14 $\mathrm{kHz}$ can be seen the percentage shown in the amount of $100 \%$ and minimum percentage of $75 \%$ in frequency 13 $\mathrm{kHz}$ sounds are probably produced by air movements in the nasal plugs. Sub frequency of $10 \mathrm{kHz}$ has a value of $649.89 \times 10^{3}$, and $14 \mathrm{kHz}$ with anti-log value of $782.82 \times 10^{3}$. Frequency of the sounds produced by a bottlenose dolphin ranges from 0.2 to $150 \mathrm{kHz}$. The lower frequency vocalizations $(0.2$ to $50 \mathrm{kHz})$ are likely used in social communication. Social signals have their most energy at frequencies less than $40 \mathrm{kHz}$. Higher frequency clicks (40 to $150 \mathrm{kHz}$ ) are primarily used for echolocation.
\end{abstract}

Keywords: Bioacoustics; Bio sonar; Indo-Pacific bottlenose dolphins; Click sound; Intensity; Frequency

\section{Introduction}

Bio sonar signals dolphin radiated along the beam axis of an Atlantic bottlenose dolphin resemble short transient oscillations. Bioacoustics is a science that combines biology and acoustics, the science has long been developing since 1980 . Bioacoustics usually refers to research on the production of sound, dispersion through elastic media, and reception in animals, including humans. This involves neurophysiology and anatomy for the production and detection of sound, and the relationship with the acoustic signal dispersion medium. The findings in this area provide evidence for us about the evolution of acoustic mechanisms, and evolution of animals that can be applied in the science of acoustics [1].

Part of the sound of the best known is the frequency, i.e., the number of vibrations of sound waves per second. Sound consists of a mixture of a variety of frequencies, therefore the sound is said to have the quality and colors are characteristic. A quantity which is closely related to the frequency is the wavelength $(\lambda)$. Wavelength is the distance between the two wave fronts is closest to the displacement and velocity of particles together in a field of flat sound field. If the frequency ( $\mathrm{f}$ ) and the wave velocity $\mathrm{c}$ are known, then the wavelength can be determined by the formula [2].

$$
\lambda={ }_{f}^{c}
$$

There has been a preponderance of evidence that implicates the nasal area of the dolphin as the site of sound production [3]. Used an array of contact hydrophones to measure dolphin sonar signals and obtained results that placed the sound source at a depth of $1.5-2.0 \mathrm{~cm}$ from the surface in the vicinity of the nasal plug. According in $[4,5]$ used high speed $\mathrm{x}$-ray motion pictures to observe movements of the laryngeal and nasal region associated with sound production in live phonating Tursiops truncatus, Tursiops gilli, and Stenella longirostris.
These are the same trials examined by [6]. This examples of the signal waveform for the same click measured by the hydrophones at the different azimuth for two of the hydrophone configurations. An example of the signals detected by the hydrophone (Figure 1). Sound dolphins have the lowest intensity value of $28.03 \mathrm{~dB}$ and highest is $32.01 \mathrm{~dB}$. Parameter salinity $30 \mathrm{ppm}$ and temperature of $23^{\circ} \mathrm{C}$ with a pool depth of 4.4 meters. Range frequency the highest is $14-16 \mathrm{kHz}$ and intensity the highest $23 \mathrm{~dB}$ at the first day after meal a click sound [7]. Science of sound production is science in which there are bioacoustic method, previous research bioacoustics in freshwater fish according in $[8,9]$, but in research about against salinity change used freshwater fish according in $[10,11]$. Research in sound production with whistle and click sound of dolphins (Tursiops aduncus), according in [12-14] (Figure 1).

Marine mammals are capable of echolocation is an incredible ability to distinguish objects with good detail. This is presumably because the bones in her skull had been arranged to form a parabolic reflection that focus sound in the forehead [15]. Melon, waxy-shaped organ located in the forehead and a lens, focusing the sound produced in the nasal plugs so that the sound will be emitted in the direction desired by the marine mammals. At the same time, the sound waves bounce off

*Corresponding author: Muhammad Zainuddin Lubis, Department of Marine Science and Technology, Bogor Agricultural University, Kampus IPB Dramaga Bogor, JI. Raya Darmaga, Bogor, Jawa Barat, 16680 Indonesia, Tel: 622518628448; E-mail: lubiszainuddin@gmail.com

Received May 04, 2016; Accepted May 28, 2016; Published June 08, 2016

Citation: Lubis MZ, Wulandari PD, Harahap MS, Tauhid M, Moron JR, et al. (2016) Bioacoustic: Percentage Click Sound of Indo-Pacific Bottlenose Dolphins (Tursiops Aduncus) in Captivity, Indonesia. J Biosens Bioelectron 7: 207. doi:10.4172/21556210.1000207

Copyright: $\odot 2016$ Lubis MZ, et al. This is an open-access article distributed under the terms of the Creative Commons Attribution License, which permits unrestricted use, distribution, and reproduction in any medium, provided the original author and source are credited. 


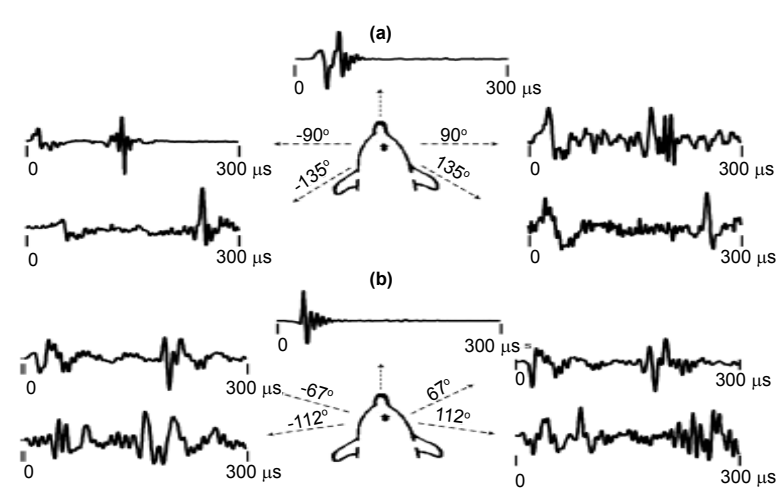

Figure 1: Examples of the signal for the same click [6].

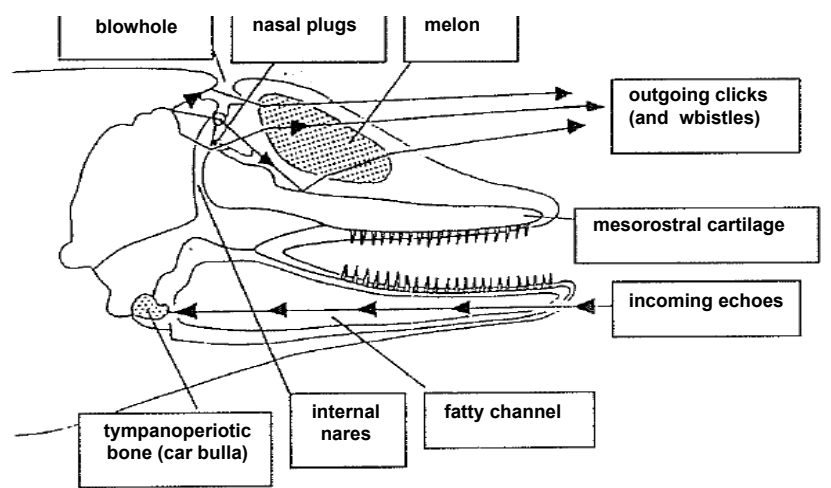

Figure 2: Production and receipt mechanism sound for bottle nose dolphin (Tursiops aduncus) [17].

objects back will be channeled through fatty channel, which contains oil and is located in the lower jaw, until it reaches the inner ear [15]. Distribution of sound can be made more precise and meticulous with the help of froth bubbling [16]. The mechanism of sound production and reception in the bottle nose dolphin (Tursiops aduncus) can be seen in (Figure 2).

Research on dolphin sounds a Quantive [16-19]. A dolphin has two dorsal bursa/phonic lip complexes, which can operate independently and simultaneously. Bottlenose dolphins can produce both clicks and whistles at the same time. All three researchers conducted a study on the distribution of dolphins in the Pacific Ocean and perform application of science bioacoustics toward the sound spectrum and distinguish each species of high and low frequencies. Marine mammals are capable of echolocation is an incredible ability to distinguish objects with good detail. This is presumably because the bones in her skull had been arranged to form a parabolic reflection that focus sound in the forehead [15]. Dolphin doesn't have vocal cords in its larynx. Sounds are probably produced by air movements in the nasal passage. The frequency of the sounds produced by a bottlenose dolphin ranges from 0.2 to $150 \mathrm{kHz}$. The lower frequency vocalizations (about 0.2 to 50 $\mathrm{kHz}$ ) are likely used in social communication. Social signals have their most energy at frequencies less than $40 \mathrm{kHz}$. Higher frequency clicks (40 to $150 \mathrm{kHz}$ ) are primarily used for echolocation [15].

\section{Research Method}

We made the recordings between in May 2016 in captivity,
Indonesia with two indo-pacific bottlenose dolphins (Tursiops aduncus). Sounds were recorded with a High Tech SQ 03 hydrophone

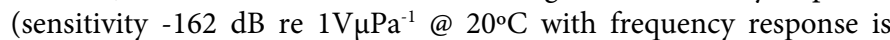
$\pm 1.5 \mathrm{~dB}$ from $7 \mathrm{~Hz}$ to $22 \mathrm{kHz}$ ) placed just above the rim of a territorial in aquaria with connected to Sea Phone Sensor (Dolphin Ear), with recording software is Wavelab 6 . Sounds were digitized at a rate of 22 $\mathrm{kHz}$ (16 bit resolution) with Wavelab 6 software and analysed with Raven Pro 1.5 software with sound duration at rate of $500 \mathrm{~ms}$ (Cornell Lab of Ornithology).

\section{Result and Discussion}

\section{Characteristics of dolphin sounds}

The resulting sound of dolphins is divided into three categories. (1) The sound of click is used in echolocation [20]. (2) Voice pulsed radiating often described as squawks, yelps, barks and others [21]. (3) The whistle sound is air-tight band with a frequency modulated. According to Madsen et al. [22] whistle function for communication. Dolphins can emit various amplitude sounds for communication in the exchange of information. Examples noise spectrum processed using Wavelab 6 software used is the result of recording dolphin sounds of Indo-pacific bottlenose dolphins (Tursiops aduncus) (Figures 3 and 4).

There is completely example of the sound spectrum that is processed using software Wavelab 6 used is the result of recording dolphin sounds of Indo-pacific bottlenose dolphins (Tursiops aduncus). Color spectrum looks brighter is the signal or the noise from the center of dolphins. With a color bar that is shown by the brighter (high) is the source of the sound or voice center. The high value of the linear intensity with bright colors produced on the noise spectrum of dolphins Dolphin. The top and bottom is the voice that comes together with one another, but results of the following view is a view that issued stereo. Figure 4 showed of click sound with range time $0-8.20 \mathrm{~ms}$, and has highest power in color bar $100 \mathrm{kU}$. Frequency with maximum intensity percentage clicks sound show in (Figure 5). Click sound power have range $80-100 \mathrm{kU}$ with $-3 \mathrm{~dB}$ according in [23-25]. Frequencies with maximum intensity percentage click sound can be seen in (Figure 6).

Figure 5 showed graph of click sound frequency dolphins that releases a clicking sound with a frequency of $7 \mathrm{kHz}$ and $14 \mathrm{kHz}$. Subfrequency sound generated from the image above that $7 \mathrm{kHz}, 10 \mathrm{kHz}$, and $14 \mathrm{kHz}$. The frequency of $7 \mathrm{kHz}$ has anti-log value is $647.08 \times 10^{3}$ with the percentage is $83 \%$ and the frequency of $14 \mathrm{kHz}$ has anti-log value $782.82 \times 10^{3}$. Sub frequency of $10 \mathrm{kHz}$ has a value of $649.89 \times$ $10^{3}$, and $14 \mathrm{kHz}$ with anti-log value of $782.82 \times 10^{3}$. The percentage of the maximum intensity in the frequency of $14 \mathrm{kHz}$ can be seen the percentage shown in the amount of $100 \%$ and a minimum percentage

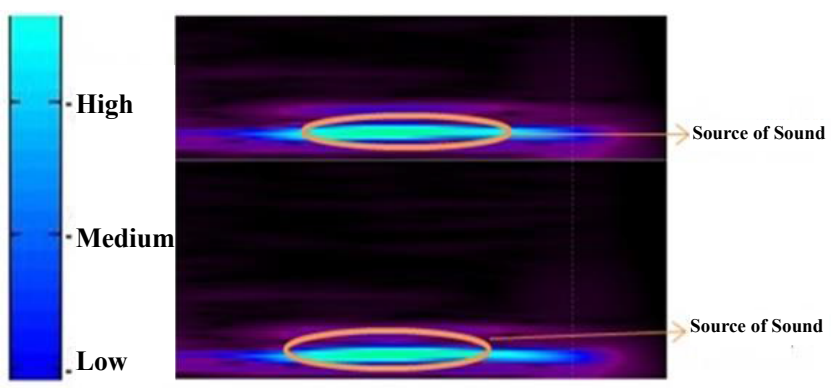

Figure 3: The spectrum of the sound generated using Wave lab 6 software [29]. 

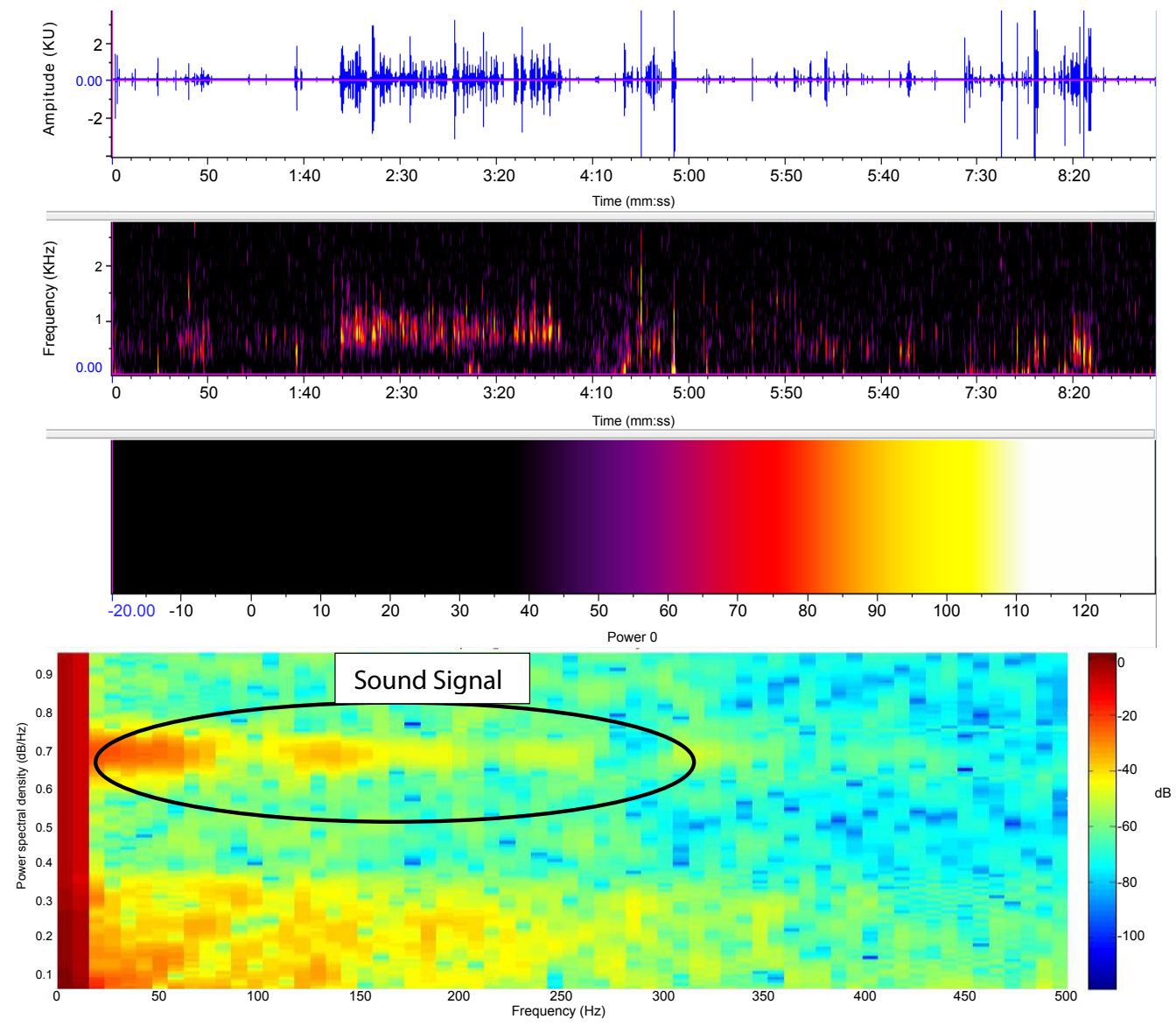

Figure 4: Click sound of Indo-pacific bottlenose dolphins [29].

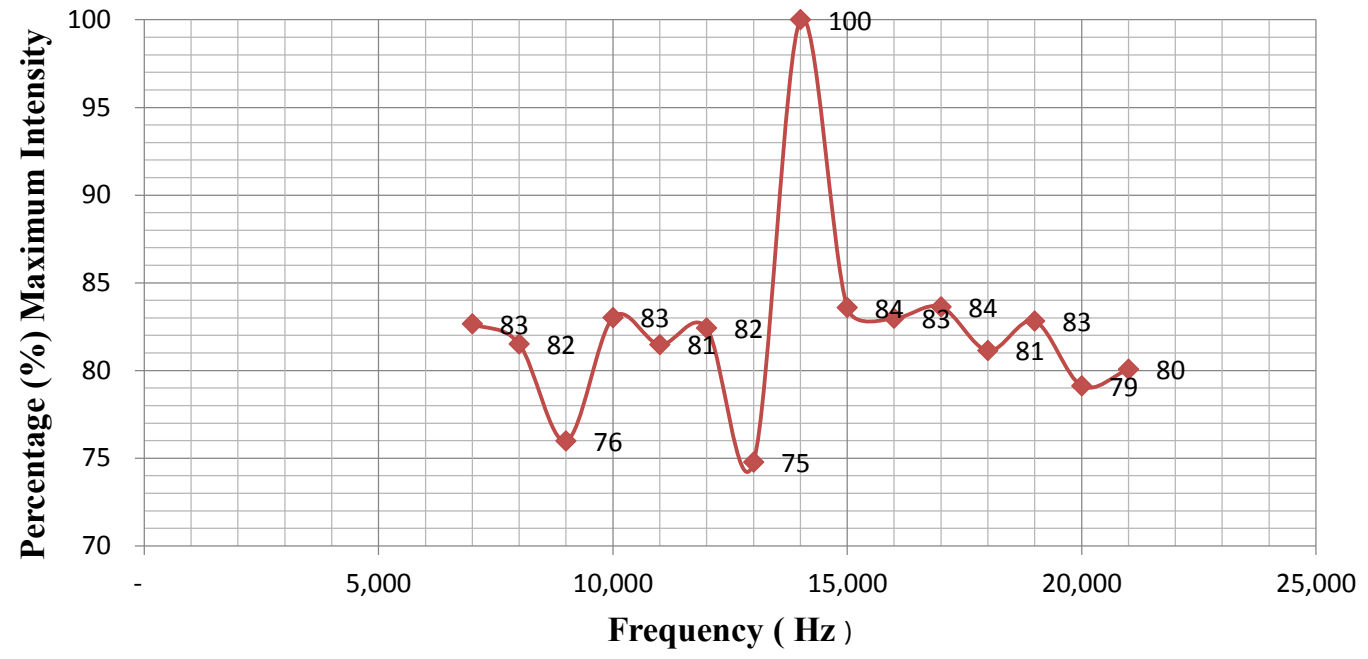

Figure 5: Frequency with maximum intensity percentage click sound [29].

of $75 \%$ in frequency $13 \mathrm{kHz}$. In paper of Freitas et al. [26] click sound common bottlenose dolphin (Tursiop aduncus) produces a clicking sound in the frequency range to $14,000 \mathrm{~Hz}-15,000 \mathrm{~Hz}$, with a range that is $20-25 \mathrm{~dB}$ intensity, it can be explained that the research conducted in captivity, Indonesia has range, frequency and intensity of the same. According to Wahlberg M et al. [27], Lubis MZ [28] Wulandari [29] describes the value of the intensity of the clicking sound is generated by using an index of voice transmission $-3 \mathrm{~dB}$, the results obtained that the 
Citation: Lubis MZ, Wulandari PD, Harahap MS, Tauhid M, Moron JR, et al. (2016) Bioacoustic: Percentage Click Sound of Indo-Pacific Bottlenose Dolphins (Tursiops Aduncus) in Captivity, Indonesia. J Biosens Bioelectron 7: 207. doi:10.4172/2155-6210.1000207

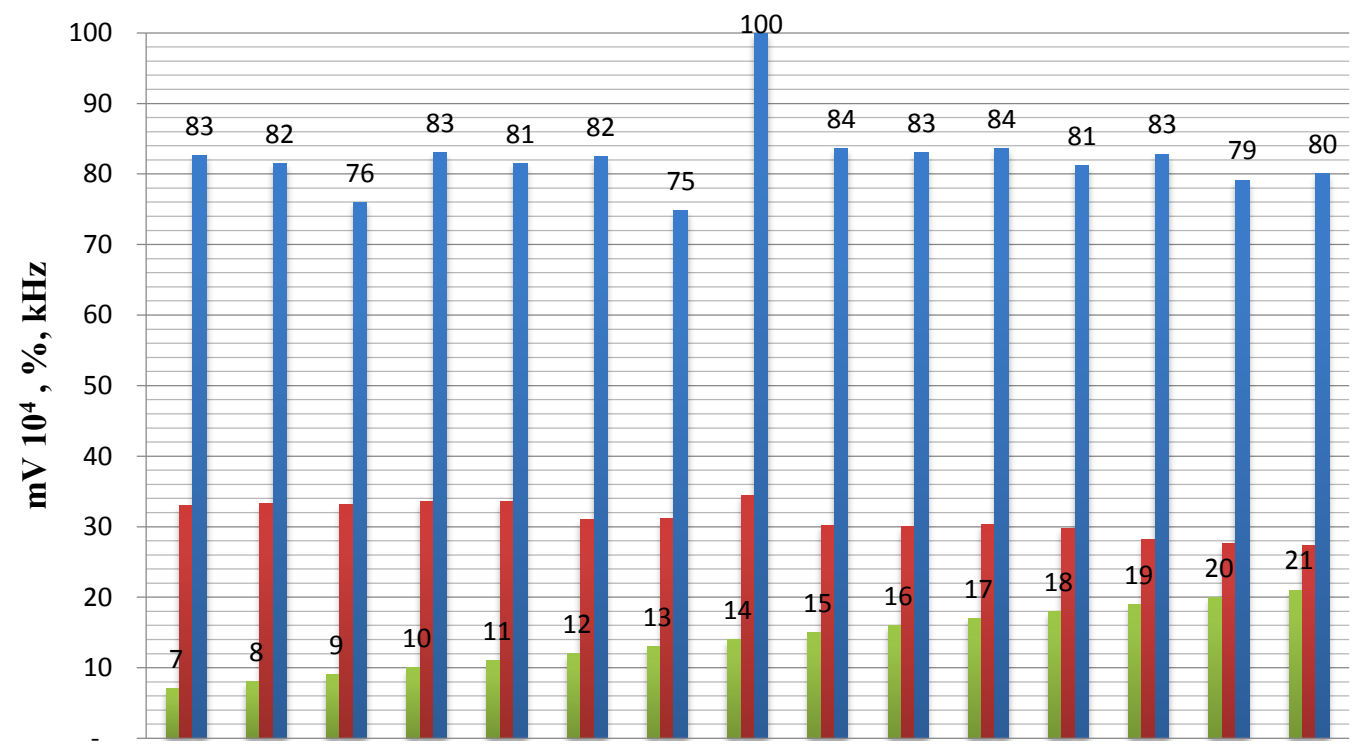

Figure 6: Graphs of frequency with $\mathrm{mV}, \mathrm{Hz}$ and \% click sound [29].

clicking sound of the common bottlenose dolphin (Tursiop aduncus) had a higher intensity is $29 \mathrm{~dB}$ tursiop truncatus than $26 \mathrm{~dB}$. Research has been done before, namely Jensen [30] and Erbe [31] show that the value range intensity $(\mathrm{dB})$ and frequency range as well as the resulting percentage has similarities with the research conducted in captivity, Indonesia.

Figure 6 showed frequency graph click sound of dolphins that releases a clicking sound. Blue color is percentage, green is frequency, and red is intensity with a frequency of $7 \mathrm{kHz}$ and $14 \mathrm{kHz}$. Subfrequency sound generated from the image above that $7 \mathrm{kHz}, 10 \mathrm{kHz}$, and $14 \mathrm{kHz}$. The frequency of $7 \mathrm{kHz}$ has anti-log value is $647.08 \times 10^{3}$ with the percentage is $83 \%$ and the frequency of $14 \mathrm{kHz}$ has anti-log value $782.82 \times 10^{3}$. Frequency sub frequency of $10 \mathrm{kHz}$ has a value of $649.89 \times 10^{3}$, and $14 \mathrm{kHz}$ with anti-log value of $782.82 \times 10^{3}$. The percentage of the maximum intensity in the frequency of $14 \mathrm{kHz}$ can be seen the percentage shown in the amount of $100 \%$ and a minimum percentage of $75 \%$ in frequency $13 \mathrm{kHz}$. It shows a clicking sound produced by dolphins has a high fluctuation is at a frequency of $14 \mathrm{kHz}$.

\section{Conclusion}

Sound frequency range of Indo-pacific bottlenose dolphins in captivity, Indonesia was between 13.211-15.245 Hz. The percentage maximum intensity in the frequency is $14 \mathrm{kHz}$ can be seen the percentage shown in the amount of $100 \%$ and a minimum percentage of $75 \%$ in frequency $13 \mathrm{kHz}$ sounds are probably produced by air movements in the nasal plugs.

\section{References}

1. Simmonds J, MacLennan DN (2005) Fisheries acoustics: theory and practice. (2nd edn.), Blackwell, Scotland.

2. Ackerman E (1988) IImu Biofisika. Airlangga University Press, Surabaya pp: 734-736.

3. Diercks KJ, Trochta RT, Greenlaw CF, Evans WE (1971) Recording and analysis of dolphin echolocation signals. J Acoust Soc Am 49: 1729-1733.

4. Norris KS, Dormer KJ, Pegg J, Liese GT (1971) The mechanism of sound production and air recycling in porpoises: A preliminary report. In Proceedings of the VIIIth Conference on Biological Sonar Diving Mammals, Menlo Park, CA.
5. Dormer KJ (1979) Mechanism of sound production and air recycling indelphinids: Cineradiographic evidence. J Acoust Soc Am 65: 229-239.

6. Au WWL, Branstetter B, Moore PW, Finneran JJ (2012) The biosonar field around an Atlantic bottlenose dolphin (Tursiops truncatus). J Acoust Soc Am 131: $569-576$.

7. Wulandari PD, Pujiyati S, Hestirianoto T, Lubis MZ (2016) Bioacoustic characteristic click sound and behaviour of male dolphins bottle nose (Tursiops aduncus). J Fisheries Livest Prod 4: 1-5.

8. Lubis MZ (2014) Bioakustik stridulatory gerak ikan guppy (poecilia reticulata) saat proses aklimatisasi kadar garam. Institute pertanian bogor, Bogor pp: $1-26$.

9. Mutiara MT, Pamungkas IR, Lubis MZ, Putri DA, Wulandari PD (2014) Studi bioakustik pergerakan ikan guppy (Poecilia reticulata) sebagai diversifikasi pakan ikan cakalang (Katsuwonus pelamis). Institute pertanian bogor, Bogor pp: 1-10.

10. Lubis MZ, Pujiyati S (2014) The impact of acclimatization of various salinity to againts mortalitas rate and behaviour fish guppy (poecilia reticulata) as a subtitute for fish bait skipjack (katsuwonuspelamis). Jurnal Teknologi Perikanan Dan Kelautan.

11. Lubis MZ, Wulandari PD, Pujiyati S, Pengaruh Penambahan (2012) Salinity to study voice bioacoustics stridulatory motion guppies (Poecilia reticulata).

12. Lubis MZ, Pujiyati S, Hestirianoto T, Wulandari PD (2016) Bioacoustic Characteristics of whistle sounds and behaviour of male indo-pacific bottlenose dolphins (Tursiops aduncus) in Indonesia. International Journal of Scientific and Research Publications 12: 7 .

13. Moron JR, Andriolo A (2015) Preliminary evidence for signature and copied whistles among spinner dolphins in the Southwest Atlantic Ocean: Beacon purpose? The Journal of the Acoustical Society of America 138: 1904-1904.

14. Bebus SE, Herzing LD (2015) Mother-offspring signature whistle similarity and patterns of association in atlantic spotted dolphins (Stenella frontalis). Animal Behavior and Cognition 2: 71-87.

15. Cahill T (2000) Dolphins national geographic society. Washington DC

16. Evans WE (1966) Vocalizations among marine mammals. Marine Bioacoustics 2: 159-185.

17. Janik, Vincent M (2009) Acoustic communication in delphinids. Advances in the Study of Behavior 40: 123-157.

18. Cook MLH, Sayigh LS, Blum JE, Wells RS (2004) Signature whistle production in undisturbed free-ranging bottlenose dolphins (Tursiops truncatus) Proceedings of the Royal Society, Series B 271: 1043-1049. 
Citation: Lubis MZ, Wulandari PD, Harahap MS, Tauhid M, Moron JR, et al. (2016) Bioacoustic: Percentage Click Sound of Indo-Pacific Bottlenose Dolphins (Tursiops Aduncus) in Captivity, Indonesia. J Biosens Bioelectron 7: 207. doi:10.4172/2155-6210.1000207

Page 5 of 5

19. Azzolin M, Papale E, Lammers MO, Gannier A, Giacoma C (2013) Geographic variation of whistles of the striped dolphin (Stenella coeruleoalba) within the Mediterranean Sea. The Journal of the Acoustical Society of America 134: 694-705.

20. Caldwell MC, Caldwell DK (1979) The whistle of the Atlantic bottlenosed dolphin (Tursiops truncatus): ontogeny. In: Behavior of Marine Animals: Current Perspectives in Research. Plenum, New York 3: 369-401.

21. Caldwell MC, Caldwell DK, Tyack PL (1990) Review of the signature-whistle hypothesis for the Atlantic bottlenose dolphin. In: The Bottlenose Dolphin (Ed. by S. Leatherwood \& R. R. Reeves), Academic Press, San Diego, California pp: 199-234.

22. Madsen PT, Jensen FH, Carder D, Ridgway S (2011) Dolphin whistles: a functional misnomer revealed by heliox breathing. Biol Lett 8: 211-213.

23. Jensen FH, Rocco A, Mansur RM, Smith BD, Janik VM (2013) Clicking in shallow rivers: short-range echolocation of irrawaddy and ganges river.

24. Sayigh LS (2014) Cetacean acoustic communication. Biocommunication of Animals pp: $275-297$.

25. Lammers MO, Oswald JN (2015) Analyzing the acoustic communication of dolphins. Dolphin Communication and Cognition: Past, Present, and Future 107.
26. Freitas MD, Jensen FH, Tyne J, Bejder L, Madsen PT (2015) Echolocation parameters of Australian humpback dolphins (Sousa sahulensis) and Indo Pacific bottlenose dolphins (Tursiops aduncus) in the wild. J Acoust Soc Am 137: 3033-3041.

27. Wahlberg M, Jensen FH, Soto NA, Beedholm K, Bejder L, et al. (2011) Source parameters of echolocation clicks from wild bottlenose dolphins (Tursiops aduncus and Tursiops truncatus). J Acoust Soc Am 130: 2263-2274.

28. Lubis MZ (2016) Identification of whistle characteristics and behavior of dolphins ( Tursiops aduncus ) in the safari park Indonesia, Cisarua Bogor.

29. Wulandari PD (2016) Bioacoustics male dolphin bottle nose (Tursiops aduncus) in quarantine pool, garden safari Indonesia, Cisarua Bogo.

30. Jensen FH, Beedholm K, Wahlberg M, Bejder L, Madsen PT (2012) Estimated communication range and energetic cost of bottlenose dolphin whistles in a tropical habitat. The Journal of the Acoustical Society of America 131: 582-592.

31. Erbe C (2011) Underwater acoustics: Noise and the effects on marine mammals. (3rd edn.), A pocket handbook, JASCO Applied Sciences. 